\title{
Rhesus Isoimmunization
}

National Cancer Institute

\section{Source}

National Cancer Institute. Rhesus Isoimmunization. NCI Thesaurus. Code C113150.

The mother develops antibodies ag ainst red blood cell Rhesus antigens. This may lead to potential fetal adverse outcomes such as anemia. 